\title{
Why interpersonal communication is important in public administration?
}

Keywords: interpersonal communication, public administration

\section{Introduction}

The famous English writer and the most creative author of capitalism, Charles Dickens, once notable, said that electronic communication will never be a good substitute for the face of someone who with his soul encourages another person to be brave and true. According to the dean of management thought, Peter Drucker, the management is seen as civilization's advantage which will continue its dominant feature as long as the human civilization exists. Management is a universal process that supports and directs the variety of political, social, cultural and business objectives to final and ultimate achievement. The universal character of management stems from the fact that there is no institution without management, and there is no management without institution presence. In this sense, besides the management covering various aspects of enterprises, its branch known as Public Management covers the aspects and dimensions of institutions that are part of the public sector.

Public management, and management in general, as one of the basic organizational phenomena that constitute its core and marrow, outlines the processes of communication

\footnotetext{
*Vladimir Naumovski, University American College Skopje, Macedonia, e-mail: naum.vladimir@ yahoo.com; Leo-Paul Dana, Montpellier Business School and Princeton University, France and USA, e-mail: lp.dana@montpellier-bs.com; Gordana Pesakovic, Herzing University, USA, e-mail: pesakovic@msn.com; Filip Fidanoski, University of Luxembourg, Luxembourg, e-mail: filipfida noski@gmail.com
} 
in organization, and particularly the flow of interpersonal communication, both within and outside the institution. The need to properly set communication rules, in terms of effective information exchange, has a priority role for the management success and for the successful functioning of the organization, whether it applies to private sector, which includes micro, small, medium and large enterprises, or the public sector, which includes public institutions. Interpersonal communication is becoming one of the most important factors for development and establishing of the public sector institutions, and the development of society in all of its segments. It is universally recognized value that works and can be used as an indicator for measuring of success and quality of public services, through the lens and the eyes of their users.

In the words of Ichak Adizes, management is a process of making and implementing of decisions, which largely includes institutional changes. Many proposed models can be a good basis for drafting, implementation and monitoring of strategies for improving the quality of administration and its interpersonal communication to a higher level. Strategies should be based on analysis of what is to be achieved through communication and how to achieve it. Furthermore, these studies should be focused on how to gain commitment and trust by citizens in established communication relations. In this way, servants will better understand the contribution of communication at the work, and thus to institutional success.

Importantly, human resources form the creative spark in any organization. It is obvious that without productive, enthusiastic and energetic people, it is not possible for organization to communicate and achieve its goals. Communication can be defined as exchange and sharing of information between two or more parties (individuals or groups) in order to achieve mutual and purposeful understanding. A very important aspect of this statement is that irrespective of whether and how much is electronic-based, the communication represents a deeply human effort and includes individuals and groups who naturally prefer communicating face to face. In other words, they wanted to feel emotions and feelings of other people. Therefore, the communication is strongly connected with the human empathy.

Similarly, effective interpersonal communication in public sector focuses on open and direct relationship between employees and citizens, thereby results in improving their commitment, productivity and organizational performances. It contains a permanent force that brings together all organizational members and guides them in a direction towards achieving the goals. Only institutions that succeed in establishing principles of effective communication have the privilege to play the role of successful organizations in today's social conditions of change and dynamism. From scientific perspective, it is necessary for organizations to create their own capacity to develop together with technology and changes related to communication. Thus, they will be ready to apply and 
respond positively to the new principles, channels and modes of communication that will contribute to the set requirements and expected achievements of the organizations.

There is no doubt that interpersonal communication is a constitutional element in all institutional roles and arrangements. The relationship between interpersonal communication and institutional success has always been the point that pervades research in areas where it stretches, from seeking for the roots of interpersonal communication in organizational terms, until its practical contribution to the quality of services the institution provides. Essential wisdom that can be drawn is that all surveys have a common denominator, which suggests that interpersonal communication and the organization are related to different levels and in many ways.

The results and benefits of effective interpersonal communication are evident on a daily basis. Hence, all organizations must observe and evaluate how their members communicate with the clients, because it is very likely that the development of institutions depends on the ability of employees to share a sensitive information with citizens.

In line with these reasons and motives, we have tried to give a clearer view on the institutional communication of public servants in relation to citizens, but solely through its interpersonal context. The work is composed of several parts, through which the various ideas of general interpersonal communication are transmitted in a very accurate way, represented at theoretical, economic - legal and practical level. Thus, the first part of the paper explicates the theoretical tenets of interpersonal communication, and communication in general, referring to its definition, process, elements and potential barriers. This part is mostly based on the studies from USA and UK, as countries with top publications and researches about communication. Further, special attention is given to the economic, but also the legal framework for interpersonal communication in the Republic of Macedonia, determined by numerous laws, bylaws and developed by numerous reforms. The most significant of which are also presented in this paper.

\section{Defining the communication and its interpersonal dimensions}

Obviously, communication is one of those human activities that everyone can recognize, but only few can define satisfactorily. As the author Lee Thayer points out, communication is a good example of everything that is more talk than actual course (Rogers, Rogers, 1976).

The literature that treats communication encounters different interpretations and definitions of this term. Simply, communication could be understood as a concept or condition for exchange of information between entities. Some authors believe that communication is a necessary prerequisite to the person-person relationship, others believe that it is a result of it. Otherwise, communication can be seen as a mechanism of 
mutual relations which establishes contacts, as well as set of all means and methods for transferring information in order to influence the behavior of people. It can also be defined as a two-way process that consists of sequential elements. Understanding this process allows the analysis of communication examples and designing communication programs which are suitable to the organizational needs.

Dozens of different definitions explain the communication structure. Yet, there is almost general consensus that communication occurs at four levels, such as intrapersonal, interpersonal, organizational and macro-social (Hargie et al., 1999). Each of these levels has a special place and a different position in the daily people interactions, starting from different situations and differences in the context in which they take place. At the level of interpersonal communication, the focus of the study of communicative relationships is narrowed and fixed between two persons or in frame of a very small group. This level includes analysis of the relationship development, maintenance and potential termination, acquisition of communicative abilities and skills, communication dysfunction, as well as professional communication, which represents an area of particular interest in the paper.

Interpersonal communication is considered to be effective at the moment when it achieves the desired reaction and response from the recipient. There are considerations and circumstances under which it is suggested that for communication to occur mutuality of opinion should be established. However, the establishment of mutuality of opinion is not always as easy as it seems. Consequently, many efforts to communicate are watched or unsuccessful. Nevertheless, if good coordination and communication is established, that creates a basis for setting up a system in which everyone performs their task to their personal satisfaction and thus contributes to achieving the organizational goals. Good communication is no longer an alternative, but a conditio sine qua non for public organizations. It is a cornerstone of any successful institutional strategy and an essential component of how the people who use public services can assess and how well these services are being delivered.

The need for transparency and accountability in the public sector has never been greater. Accordingly, raising the voice and increasing the user's choice of public services means that an open, honest and two-way communication is the only sustainable way for organizations who want to build their reputation and strengthen ties with their communities. Communication in the public sector should no longer be considered and practiced as a linear activity. In general, communication should not start with creation of the message and end with its transmission. Effective communication is a circular process which means to listen, to learn and to share the learned knowledge with other people. And once it is done, it should be done again. Organizations in the public sector must learn to listen; to listen to their stakeholders, and especially to their users. What are their needs? How they want their needs to be met? But it is not just about listening. Public 
institutions must also learn to learn; to learn from their users and their experiences. This does not end here. Public institutions should share the results of their learning and show the beneficiaries of their services, how they respond to their needs, and in the context of improving the products coming from the public administration (http://www. publicsectorpr.co.uk/good-communication.php).

Although the pressures and priorities of the public sector constantly undergo remodeling and changes, there caused and affect a significant changes in the expectations and demands of the entities. Therefore, it is essential to retain the required level of listening, learning and sharing of knowledge. This circular approach to communication is far more efficient and more effective than the linear approach, because it begets trust between the organization and clients. Trust is important because it is the basis from which everyone draws and builds a long-term and successful relationship. With trust comes credibility. So, if credibility and trust are important for organizations, then for these organizations the two-way communication is also important (http:/www. publicsectorpr.co.uk/good-communication.php).

\section{Designing the communication process}

The organizational communication in its infancy was associated with business information and early mass communication, presented in various publications published predominantly in the period from the 30 s to 50 s of the last century (Berger, 2008). Until then, organizational communication, as a discipline, has been covered only in the lectures of a few professors who had a special interest in business speaking and writing. Nowadays, this area is established with its own theories and empirical researches, substantially different than other communication subfields and approaches to organizational relations. Several seminal publications stand out as works that expand the scope and recognize the importance of organizational process and begin to use the term organizational communication. Namely, Nobel laureate, Herbert Simon, has paid special attention in his publications to the so-called systems of organizational communication, emphasizing that communication is absolutely essential for organizations (Simon, 1947).

Hence, and in order to facilitate the design of the communication process in the institutions, it can be defined as the transfer of information and their meaning from one individual or group to another individual or group. Key element in this definition is the meaning. Communication has the transfer of meaning as a main objective. The process of communication is successful only and solely when the recipient understands the basic idea as the sender intended. Both parties must agree not only for the transmitted information and message, but also for the importance of that information. How does the 
transferring of an idea from one person to another function? Although this can be seen in some futuristic science - fiction movies and books, we cannot only look hard at another person and transfer the meaning directly from ours to their mind. This is done by including in the sensitive process of communication (read more in Guffey, Loewy, 2011).

\section{Potential communication barriers}

If anything can go wrong, it will. The famous Murphy's Law can explain one aspect of organizational communication, and that is its possible failure. Although knowledge of the communication process and the skill of its implementation are the basis for efficient and effective communication, they do not guarantee success. The sender must also minimize or eliminate barriers that could impede and impair the effectiveness and efficiency of the process. Communication obstacle or barrier is any factor that affects the success of the communication process per se. These barriers can occur between any two steps in the communication process or can influence all steps in a given process. The most crucial barriers, barriers of essential significance are the following (Hamilton, 2008; Krizan et al., 2008):

The selection of words that are too heavy, too technical or too easy for the recipient, can pose a serious communication barrier. If the words are too heavy or too technically complex, the recipient cannot understand them. On the other hand, if the words are too simple, the reader may become bored or insulted. The sender must be careful when choosing the right words for their messages. Misuse of a word (e.g. continuous, rather than constantly) can disrupt the communication process, which will reflect badly on the writer or speaker. The wording should also be carefully selected during communication with people with different mother tongue. These recipients may not be familiar with the colloquial language or the informal way in which the language is used, and the idioms which it contains.

Grammar, sentence structure, punctuation and spelling. Incorrect grammar and poor sentence structures could hinder understanding of the spoken or written messages by the recipient. Punctuation and spelling errors can create a barrier to understanding the written message. As the number of errors increases, readers often stop reading or following the content. These errors indicate that the person who sent the message either does not know the basics of the language we use or is too irresponsible to fix the problem. As a result, the sender may lose credibility.

Physical form of the message. The appearance of the message affects its readability and influences the acceptance of its contents. Clumsy adjustments, weak or too strong light on writings, messy paper and poor handwriting, can distract the reader and become a serious barrier to effective communication. Using emoticons and writing the whole text 
in capital letters, can be a special barrier to the use of electronic mail. The sender should check every document before sending in order to ensure that their views are not intertwined with one's potential for success.

Personal appearance of the sender. The credibility of the oral message can be reduced if the sender looks unattractive or unacceptable to the recipient. In addition, unintended nonverbal signals can distract the recipient and it can affect the way the oral message was received. For example, if you laugh when you say a bad news, your motives and reasons may be questionable and can cause dilemmas to the whole process. If the credibility of the message is brought into question, the quality of the recipient's understanding, acceptance and response will also suffer severe consequences and declines. For success in verbal communication, the sender should be sure that their clothing, cleanliness, face and body movements are appropriate to the professional status, reputation and current situations they are facing. For example, a man dressed in a tuxedo at a party or at a beach is as inadequate as an individual who is wearing a bathing suit in the office.

Environmental factors. Environment, in which communication occurs, can significantly associate with the success of the message. Noisy machines in an area where a supervisor is trying to talk to an employee may be an important limiting factor. Similar is the situation with a supervisor whom the table separates from the employee during the meeting, which can intimidate the worker and limit his or her ability to give a proper response to the message. Other examples of an environment that may become barrier to efficient and effective communication include ambient temperature, odor, light color and distance. The sender has a responsibility to eliminate the factors of environment that have the potential to become a communication barrier. For instance, if the room in which the oral presentation should take place is too hot, the sender should try to adjust the temperature or to keep the windows open. If the recipient cannot read the message because of poor light, the sender should ensure the provision of better lighting. The barriers which are located in the external and internal environment should be eliminated or reduced before the start of communication.

Ability of the recipient. If the recipient has certain disabilities which may generate further communication barriers, the sender can remove or offset the barrier by a careful choice of the message form and by providing appropriate mechanisms to ensure feedback. Most solutions are clear choices. The increased volume, printed text or sign language interpreter can help overcome potential barriers associated with hearing. When vision impairment threatens and attacks the success of the written message, the text message can be increased or it can be transmitted verbally. Effective communication is focused on the ability of recipients and deals with it in order to guarantee the communication success. 
Ineffective listening skills. Indeed, the failure to listen is a common barrier to successful verbal communication. Diogenes Laertius once famously stated that we have two ears and one tongue so that we would listen more and talk less. To listen effectively and efficiently is not easy at all. One of the reasons why listening becomes a challenge is that most people speak 150 to 200 words per minute, but they are capable of listening 400 to 500 words per minute. This difference allows listeners, or their minds, to wander on different issues than the topic contained in the message. Additionally, listeners can begin to think about how they will respond to the message. Listening is a skill that can and must be learned. Senders can use several methods to overcome the barrier by the recipient, as represented by poor skill of listening. The inclusion of phrases such as consider the following point, it is particularly important, signals to the recipients to listen carefully. Asking questions periodically will help determine the listener's level of understanding. In some circumstances, the audience can be encouraged to improve her or his ability to listen. One of the most effective ways to possibly remove the bad hearing as a communication barrier is to improve the message's quality and the way it is transmitted. A thorough analysis of the audience before designing and sending the message will help senders to better plan, design, organize and send appropriate oral messages.

Other communication barriers. Several of the most commonly mentioned and detected communication barriers and ways to remedy them were listed in the previous paragraphs. In an effort to improve communication efficiency, we may also face other barriers that must be removed. For example, some practices related to communication barriers include lack of interest, lack of knowledge, different cultural perceptions, linguistic difficulties, biases and partiality. The sender must do everything possible to remove these inputs of inefficient communication, related to communication barriers.

Finally, realizing the obstacles one may have doubts that effective organizational communication is an attainable goal. Of course, all potential obstacles to effective communication cannot be anticipated. However, if it is to be successful, one must work hard to master the skills required in this complex process. Any additional effort would be considered a valuable and important step in improving organizational communication and performances.

\section{Focus on interpersonal communication and behavioral aspects}

Although no one can fully claim that lack of communication is the sole cause of organizational problems, yet it is often one of the root causes. Communication may figuratively be treated as bloodstream within organization, its oxygen, brain, central nervous system, arteries, highway through a moving institution, adhesive strength that 
connects the parts in a whole or gas which drives the vehicle (Hargie et al., 1999). At this point, perhaps, the importance of communication in an organization, especially interpersonal, can be compared with a very simple sense of what is love - that cannot be

\section{quantified, but it can feel like the need for living.}

The interpersonal communication, or face to face communicating, is a medium that is highest in the wealth of information, which shows the amount of information that the communication providers can implement and the extent to which the medium allows the sender and receiver to reach a mutual understanding. When individuals communicate face to face, they not only realize the advantages of verbal communication, but can also interpret each other's signals such as facial expressions and body language. Interpersonal communication also delivers instant feedback and solves the moments of confusion, ambiguity or misunderstanding. Management by walking around or management of wandering around is one of the techniques of interpersonal communication. This concept has a tremendous efficiency for many managers at all levels, because with its help numerous formal meetings with subordinates can be avoided. In other words, informal conversations with employees can be practiced. The application of this technique, despite significant interpersonal abilities and skills, requires a high level of interpersonal and emotional intelligence, which in turn is directly related to the successful implementation of this kind of informal communication (Jones, George, 2016).

Interpersonal intelligence refers to the ability to read, sympathize and understand others. Individuals with interpersonal intelligence are good with people and achieve significant improvement and progress toward social interaction. Instead of considering that some are born with it and others are not, interpersonal intelligence can be improved by broadening the scope of understanding of human behavior, motivation and exercise of certain types of relations in interpersonal interaction. The knowledge from the field of sociology and psychology are particularly useful for understanding human needs and providing mechanisms that will help in giving a precise answer as to provide for efficient and effective communication at the workplace.

In this sense, the psychologist Abraham Maslow developed the concept of a hierarchy of needs, which shows how people are progressing. In our society, most people show reasonable satisfaction of their two lower levels of needs: 1) physiological needs (food and other basic subsistence needs) and 2) their safety and protection (shelter and protection from the elements of physical danger). Beyond these two basic levels of needs, people progress to meet the other three higher levels in the hierarchy of needs; 3) social needs for love, acceptance and belonging; 4) ego or esteem, a need to be heard, valued and loved; 5) self-fulfillment, including the need to achieve the fullest potential and result through professional, philanthropic, political, educational and artistic channels. 
As people meet the needs of one level, they move to the next. Effective communicators are able to identify and anticipate the needs of different levels for individuals or groups. For instance, advertising is designed to meet the needs of different levels. Luxury car and dream vacation are advertisements to satisfy ego needs, while teeth whitening and antiaging products respond to social needs and identity. Advertisements for health and fitness, and environmental advertisements carry messages that are targeted to the needs for safety and security. The effort to help employees meet their needs is essential because the satisfied worker is generally more productive than the dissatisfied worker. In communication activities, the sender more than likely appeals to the recipient if they have correctly identified their need (Lehman, DuFrene, 2011).

Generally, people engage in communication with others in the hope that the outcome can lead to mutual trust, mutual satisfaction and psychological well-being. Communication is the agent for exchange of information about things, ideas, tasks and themselves. Each communication interaction, whether informal or formal, provides emotional and brain effects that can have either a positive or a negative impact on the emotions that we carry for ourselves and others. Tapping on the back by a supervisor, receiving congratulations via phone call or text message, and hearing by another person, are examples of everyday positive signals. Negative signals may include obtaining a malicious comment, avoidance or switching off the conversation and receive rebuke from a superior. Paying attention to the importance of movement, managers can greatly improve communication and people's feelings about their work.

Further, as relationships develop, the people involved in communication continue to get to know each other as well as themselves. This precisely captures the essence and the essential wisdom of surface elements that make up the Johari Window. Area I from Johari Window shows free or open space and represents what we know about ourselves and what others know about us. Area II is blind area which indicates those things that others know about us, and we do not know for ourselves. For example, this space represents the fact that we are the only ones who cannot physically see ourselves, as we really are. Things we know about ourselves, but others do not know about us represent hidden or secret region III. Area IV includes outfield, things that we do not know about ourselves and that others do not know about us, as is our ability to work with problems in emergency situations if we have never, until then, faced them (Lehman, DuFrene, 2011).

Each area of the window may vary in size and the extent to which we learn about ourselves and are ready to discover things for ourselves and for others. Reciprocal exchange occurs at the moment when humans develop trust between each other. When there is confidentiality, proves that he or she can trust each other and trust is strengthened and could lead to an expansion of the open area of the Johari Window. Usually, we are 
ready to tell people things which are not entirely personal. But we also share personal thoughts, ambitions and inner feelings only with selected and special people, those who we believe and can trust. Relationships which exist between supervisor and employee, physician and patient, and lawyer and client are relationships of trust, but only in specific areas. In the most intimate relationship with the extensive use of jargon, brothers, sisters and parents express deeply personal feelings and confide in each other (Lehman, DuFrene, 2011). All in all, Johari Window is regarded as a pretty good model for resolving the perceptual processes that are performed in interpersonal relationships, which are essential for communication between two people (Griffin, 2006).

The idea that trust and openness can lead to better communication between the two parties, also applies to groups. Managers involved in the organizational development deal with designing of successful organizations and build effective, small, and even selfgroups. They believe that small groups more effectively develop a high level of mutual trust between group members. The aim is to achieve emotional communication and a relationship-oriented task. To achieve this goal, the groups often engage in sessions by trying to increase the open area of Johari Window (Galpin, 1995).

In fact, interpersonal communication uses different verbal and non-verbal messages that communicate different ideas. More specifically, verbal means using words in written or spoken form, whereas non-verbal means without using words. Even though the central stage in communication is directed to the verbal messages, empirical studies show that non-verbal elements can represent more than $90 \%$ of the significance of the messages (Mehrabian, 1971). Moreover, non-verbal behavior and communication is complex, subtle and involves using multiple channels (Furnham, Petrova, 2010). Concretely, it includes the meta communication and kinetic messages.

The meta communication is a message that, despite not being expressed in words, accompanies the message which is expressed in words. For instance, "do not be late for work" communicates caution, but the sentence could imply (but not express in words) such additional ideas: "you are often late and I am warning you", or "I doubt your excuses". "Your solution is perfect", can also be transmitted as the meta communication "you are efficient", or "definitely I like your work". Whether spoken or written, it can certainly be argued that those who receive the message will be more sensitive, not by the messages expressed in words, but to the additional messages which are presented and hidden in interpersonal communication, and are not expressed by words (Lehman, Du Frene, 2011).

On another subject, people also constantly send different meanings through kinetic communication. In other words, recipients receive additional meaning to what they see and hear in the vocal and visual sense (Lehman, DuFrene, 2011): 1) kinesthetic visual communication - gestures, winking, smiles, sighs, clothing, hairstyle and all kinds of 
body movements; 2) kinesthetic vocal communication - intonation, projection and resonance of the voice. Meta communication and kinesthetic messages have characteristics that all successful and skillful communicators should consider (Lehman, DuFrene, 2011): 1) non-verbal messages cannot be avoided. Both written and spoken words carry ideas, in addition to the ideas contained in the words that are used; all activities and even the lack of action have certain significance for those who observe; 2) non-verbal messages can have different meanings for different people. If a team member smiles after giving a statement, one member may conclude that the speaker is trying to be funny, while others may conclude that the speaker was pleased that they made such a great contribution, and still others can see the smile as a sign of sociability; 3) non-verbal messages vary between and within different cultures. Not only non-verbal messages carry meanings that are different from culture to culture, but also men and women of the same culture usually show different body language. By some rule, American men are practicing less physical contact with other men than women with other women. The acceptable male body language may include a handshake or tapping on the back, while women show more flexibility in physical contact with each other; 4) non-verbal messages can be intentional or unintentional. "You are right about it" means "I agree with you" or "you are right on this, but it would be proper to get everybody else to discuss it"; 5) non-verbal messages can contradict the accompanying verbal messages and influence whether the message is understood or not. The proverb deeds speak louder than words reveals a lot about how people view the messages. For example, the image of a man who says "I am happy to be here", but also looking at the floor, talking with a weak and shaky voice and holding hands shyly in front of his body is a striking example of inconsistency and distorted mirroring messages. Since his verbal and non-verbal messages are contradictory, the audience cannot believe his words. Similarly, you can consider the negative effect of a sloppy personal appearance of a job candidate; 6) non-verbal messages can attract more attention vis-à-vis verbal messages. If a supervisor constantly looks at their mobile phone or rhythmically beats with the pen while composing statement, words cannot be registered within the mind of the employee; 7) non-verbal messages give clues about the sender's background and their motives. For example, excessive use of big words could suggest that the person reads a lot or has an above-average education, but also might suggest a need for social recognition or the insecurity of his/her social background; 8) non-verbal messages are strongly influenced by the communication circumstances. Let us suppose that two men, Ganesh and Jacob, are friends from work. When they work together, Ganesh sometimes puts his hand on Jacob's shoulder. This act may mean to Jacob no more than "we are close friends". But, suppose that Ganesh is a member of the committee that denies or derogates promotion of Jacob. Then, this same act may mean "we are still friends", but it can also cause resentment. Because of the circumstances, the same act 
now could mean something as "look, the hand that caresses you, also can stab you"; 9) non-verbal messages can be useful, but also damaging. Words or actions may be accompanied by a non-verbal message that can help or hurt, breaking the sender's goal. Meta communication and kinesthetic messages can carry something like "I am efficient in my work and attentive to others", or vice versa. They cannot be removed, but you can make it work for us instead of against us.

Despite the fact that many professionals mistakenly believe that business communication is a presentation skill, not interaction, most managers spent most of their day listening and talking to others. To listen to superiors, employees, clients and colleagues usually consumes more time than reading, writing and speaking in a joint combination. Listening is an interpersonal skill as critical as the skill of speaking. The CEO of BestBuy, Brad Anderson, explains that effective listening is central to the work culture of his young vendors that have grown in the digital era and expect, prefer two-way conversation in peer-to-peer style, rather than just a way of teaching. Anderson points out that if an employee is found to be a poor listener, they will be degraded from the CEO position immediately (Tapscott, 2008).

Benefits of effective listening habits manifest themselves in several ways: 1) good listeners are liked by others because they meet the basic human needs to be heard and loved; 2) people who listen have the skills to separate facts from fictions, effectively deal with false beliefs and prevent the situation when others use them for personal gain and benefit; 3) effective listening leads to sensitivity, tolerance and to key individuals who are essential for organizational success (e.g. employees, clients and suppliers); 4) effective listeners are engaged in continuous learning, permanent knowledge acquisition and skills that lead to greater creativity, worker's efficiency, advancement and pleasure; 5) job satisfaction increases when people learn what happens when they are being listened to, and when they participate in mutual trust that develops and comes from a good interpersonal communication. Listening depends on the ability to receive and decode the verbal and non-verbal messages. Even the most regulated and most sophisticated communication systems will not work properly and truly if people across the voicemails do not hear. Senders of voice messages must ensure that listeners will hear, as the senders of written messages must ensure that recipients are able and will read the messages. Individuals, through listening, can satisfy different needs and goals, such as social interaction, receiving information, problem solving and sharing feelings with others. Each activity can occur and refers to a different style or a full range of styles of listening (Lehman, DuFrene, 2011):

Ordinary listening. Listening for pleasure, recreation, entertainment and relaxation is the most usual kind of listening. Some people listen to music all day in order to relax the brain and mask unwanted sounds during daily routines, work periods and daily 
duties. Aspects of ordinary listening are: 1) it provides relaxing breaks of more serious tasks and supports our emotional health; 2) it shows that people are selective listeners; they hear what they want to hear; in a crowded room in which it seems that everyone talks, all the noise can be blocked and the individual can engage in conversation with someone; 3) it requires a small emotional or physical effort.

Listening for information. Listening for information includes searching data or materials. At school, for example, the professor usually has a strategy to guide the class towards the desired objectives. The professor will probably highlight several large, main points and would use evidence to prove and strengthen them. It is also very similar to some experienced negotiator or facilitator.

Intensive listening. When one listens in order to obtain information, solve problems, or persuade or dissuade (the argument), then it is intensive listening. Intensive listening involves greater use of analytical skills, necessary to proceed through the steps for problem resolving. In intensive listening, one becomes a good evaluator and magnet for ideas, development of the discussion can be followed, and there starts the analysis.

Empathic listening. Empathy occurs when a person is trying to share feelings or emotions with others. Counselors try to use empathic listening in dealing with their clients. Good friends also listen to each other empathically. Without any doubt, empathy is a valuable feature, developed by people who are skilled in human relations. In empathic listening: 1) preoccupation with one's own problems should be avoided. By talking too much, strong non-verbal signals of exhaustion are sent, while the others' desire to speak can be destroyed; 2) full empathy can never be reached, simply because there are no two people who are identical. The more similar our experiences are, however, the better we are able to put ourselves in the shoes of the other person. Listening with empathy involves real tact, combined with other good listening habits.

In sum, the practical experience shows that in certain situations a need may arise for a combination of the intense and empathic listening. Interviews to assess results, disciplinary conferences and other sensitive discussions between servants and clients require intensive listening for accurate understanding of messages and empathic listening to properly recognize the emotions.

\section{Economic-legal framework for interpersonal communication in public sector: Case of Macedonia?}

For a quality conduct of interpersonal communication of public servants in the Republic of Macedonia, it is necessary to clearly determine the position and role of public sector in carrying out economic and social functions, as well as to present the 
current favorable legal framework, which draws the scope of activities of this vital social apparatus.

The significance of the public sector is paramount. From birth to demise, our lives in countless ways are affected by the activities of the public sector (Stiglitz, Rosengard, 2015): 1) we are born in hospitals that receive public subsidies, unless they are privately owned; then our birth is recorded in public registers (our birth certificate), thus acquiring a range of privileges and responsibilities as a citizen; 2) most of us (almost 90\%) attend public funded schools; 3) almost every one of us, at some time in life, receives money from the government through various budget programs, such as student loans, social transfers due to unemployment or certain disabilities, programs to combat poverty, social security, health care and protection; 4) each of us pays taxes to the government, e.g. consumer taxes on special items and excise goods such as gasoline, alcohol, phone, using services of air travel, perfume and tires, property tax, custom's tariffs, income tax and taxes on social insurance (earned income tax); 5) a large part of the workforce is engaged in public sector, while for the rest, the government has a considerable impact in terms of employment conditions; 6) in many areas of production, regardless of whether it comes to cars, shoes or computers, profits and employment opportunities are significantly influenced by the fact whether the government allows competing companies to sell goods in the US without adequate tariffs and quotas for them; 7) governmental agencies are regulating what we eat and drink, and more, take an action and regulation activities in the housing market (houses where we live); 8) we travel on public roads and publicly subsidized railways. In most of our municipal and local communities, government and public agencies collect waste and clean the drains; 9) in some local self-governments, even the water we drink is provided by public utilities; 10) our legal system provides judicial structure and legal framework under which individuals and companies can enter into agreements with each other. In case of a dispute between two individuals, they may turn to the competent court, which should decide the present dispute; 11) without the existence of environmental regulation, many of our cities would suffocate of pollution, the water in our lakes and rivers would become unhealthy for drinking and we could never swim or use the fish from them; 12) without existence of regulations on road traffic safety, such as provisions for compulsory wearing of seat belts in cars, the number of victims and accidents on highways would be significantly higher.

All these activities which are exercised through interaction of citizens and legal entities within the public institutions in the US apply to us, too. Governmental institutions in their everyday work often make contact and serve people outside the organization, regardless of whether they call them users or citizens. Today, the government and public sector must increasingly be directed towards citizens, using positive examples from the private sector. Customer orientation plays a key role in the provision of public services. 
This requires a variety of skills related to the servant's conduct, such as communication skills and those skills that relate to the treatment of citizens with respect and understanding (Ministry of Information Society and Administration, 2011). Yet, before we move to the new campus of reforms that the Ministry of Information Society and Administration has undertaken in order to provide better interpersonal communication, it is necessary to define and determine what the legislation means under the category of administrative and public servants.

Importantly, legislation which treats this matter has suffered numerous essential amendments and decisions on annulment of certain provisions by the Constitutional Court. Thus implies institutional instability and inability to find a stable legal solution that will in the right way respond to the needs and wishes of the legislature and beneficiaries of public sector services. However, by the different texts, as well as the consolidated text of the laws, the categories entering these sectors can be clearly discerned. These laws have been modernized and follow the most sophisticated nomotechnic form.

Specifically, an administrative servant, in the sense of law, is considered a person employed in some governmental service, who performs professional, normative-legal, executive, statistical, administrative, supervisory, planning, IT, material-financial, accounting, informative, and other jobs within the competence of the body (Article 2, Paragraph 1 of the Law on administrative servants, Official Gazette of the Republic of Macedonia, No. 27/2014, 199/2014, 48/2015, 154/2015 and 5/2016).On another side, in the administrative classification, depending on the type of education, work experience, responsibility and complexity of the tasks, there are 17 titles set out, organized into four groups: I - secretaries, II - management, III - professional and administrative, and IV - assisting - professional administrative servants (Article 22, 23, 24, 25 and 26 of the Law on administrative servants, Official Gazette of the Republic of Macedonia, No. 27/2014, 199/2014, 48/2015, 154/2015 and 5/2016).

Secretary titles are: State Secretary; Secretary General; Secretary of the City of Skopje, Municipality Secretary (based in city) and Municipality Secretary (based in village).

Managerial titles are: Administrative Head (I level), Administrative Head (II level), Administrative Head (III level) and Administrative Head (IV level). Administrative Head (I level), with at least 240 ECTS credits and at least six years of professional experience from which two years at the managerial position in the public sector, or at least ten years of professional experience from which three years at the managerial position in the private sector; Administrative Head (II level), with at least 240 ECTS credits and at least five years of professional experience from which two years at the managerial position in the public sector, or at least eight years of professional experience 
from which three years at the managerial position in the private sector; Administrative Head (III level) and Administrative Head (IV level), with at least 240 ECTS credits and at least four years of professional experience from which one year in the public sector, or at least six years of professional experience from which two years at the managerial position in the private sector. People from this level should have an adequate core and special competences. Namely, Administrative Head (I level) and Administrative Head (II level) should possess a certificate for knowledge about administrative computer programs, administrative management as well as satisfactory language proficiency of one of the three most widespread languages in the European Union (proved by the relevant international certificate).

Professional and Administrative positions are: Professional Administrative Servant (I level), Professional Administrative Servant (II level), Professional Administrative Servant (III level) and Professional Administrative Servant (IV level). Professional Administrative Servant (I level), with at least 240 ECTS credits and three years of professional experience; Professional Administrative Servant (II level), with at least 180 ECTS credits and two years of professional experience; Professional Administrative Servant (III level), with at least 180 ECTS credits and a year of professional experience; Professional Administrative Servant (IV level), with at least 180 ECTS credits and no work experience. People from this level should have an adequate core and special competences. Usually, they should possess a certificate for knowledge about administrative computer programs as well as satisfactory language proficiency of one of the three most widespread languages in the European Union (proved by the relevant international certificate).

Assisting - Professional Administrative positions are: Assisting - Professional Administrative Servant (I level); Assisting - Professional Administrative Servant (II level); Assisting - Professional Administrative Servant (III level); Assisting Professional Administrative Servant (IV level). Assisting - Professional Administrative Servant (I level), with at least successfully finished secondary school, and three years of professional experience; Assisting - Professional Administrative Servant (II level), with at least successfully finished secondary school, and two years of professional experience; Assisting - Professional Administrative Servant (III level), with at least successfully finished secondary school, and one year of professional experience; Assisting Professional Administrative Servant (IV level), with at least successfully finished secondary school, and with or without adequate professional experience. People from this level should have adequate general and specific competences. Usually, they should possess a certificate for knowledge about administrative computer programs as well as satisfactory language proficiency of one of the three most widespread languages in the European Union (proved by the relevant international certificate). 
Public administration can be marked as a special segment, which as an area of significant interest and importance is regulated by a separate legal instrument in the form of law. Thus, public servant is considered a person who performs various tasks within the state and local governments, and other state authorities established in accordance with the Constitution and laws and who works in the institutions from the field of education, science, health, culture, labor, social welfare and child protection, sports, and other activities of public interest determined by law and organized as agencies, funds, public institutions and state-owned enterprises established by the Republic of Macedonia or the municipalities, the city of Skopje and the municipalities in Skopje (Article 2 and 3 of the Law on administrative servants, Official Gazette of the Republic of Macedonia, No. 27/2014, 199/2014, 48/2015, 154/2015 and 5/2016).

Legal solutions which regulate the activity of administrative and public sector also prescribe some principles of accountability, professional conduct, ethics, reliability and protection of the means of work. Servants should follow and respect several principles: equal conditions, equal access to employment, appropriate and fair representation; professionalism and competence; performance management; service - orientation; professional ethics, impartiality and objectivity; transparency and confidentiality; duties and responsibilities; preventing of the conflict of interest; and economical use of resources (Book II of the Law for employees of the public sector, Official Gazette of the Republic of Macedonia, No. 27/2014, 199/2014 and 27/2016).

There is also a very detailed classification of the positions in the public sector institutions. Hence, there are many titles set out, organized into four groups: 1) administrative servants or persons employed in the public sector institutions who are responsible for performing activities of administrative nature; 2) job positions with special authority or persons employed in the public sector institutions in the field of security, defense and intelligence who possess a special authority; 3) public servants who provide public services, i.e. persons employed in the public sector institutions to perform activities related to public interest in accordance with the law, but not of administrative nature; 4) assisting-technical persons or persons employed in the public sector institutions who are responsible for maintenance, transport security, and other assisting and technical activities which ensure the smooth functioning of institutions (Article 14, Paragraph 1 of the Law for employees of the public sector, Official Gazette of the Republic of Macedonia, No. 27/2014, 199/2014 and 27/2016).

The employment principles are identical in both administrative and public sector. So, the recruitment procedure begins with the publishing of a public announcement, and in a transparent, fair and competitive selection procedure the assessment committee would offer a position to the best candidate (Article 30, Paragraph 2of the Law on 
administrative servants, Official Gazette of the Republic of Macedonia, No. 27/2014, 199/2014, 48/2015, 154/2015 and 5/2016).

Further, for advancing the field of communication with citizens, the Law on Free Access to Public Information, requires the institutions of government and public sector to provide the citizens access to all information that are not treated as classified information. Yet, the greatest pain in the implementation of laws is the so-called administrative silence, although in most cases it is about requests, i.e. information which persons in charge of mediating in the institutions should provide without major problems. This rule, which is anticipated in the Law on free access to public information (Official Gazette of the Republic of Macedonia, No. 13/2006, 86/2008, 6/2010, 42/2014 and 148/2015) as lexspecialis, and partly by the Law on general administrative procedure (Official Gazette of the Republic of Macedonia, No. 124/2015), should put pressure on servants to answer appropriately to the requests that arrive from the citizens, within the time limit determined for providing response. The legislator, by introducing this rule, has stipulated that in any case when the public institutions will not formally respond to a request from the citizens, after 15 days it will be considered as approved. In this way, public servants should devote more time and attention to the request and cases of citizens, which directly affects the communication between these two or three groups.

In this regard, before some time Macedonian authorities launched an important initiative which has been adopted, introducing the Citizen's Charter as a response to the request to address the problems faced by citizens in their daily interaction with the public institutions. The concept of Citizen's Charter fosters trust between those who provide services and the beneficiaries. It aims to present measurable standards of service obtained through consultations between servants and users. The Charter is a declaration that the authorities publicly commit in terms of service's standard, simultaneously allow citizens access to services which personally concern them, and an opportunity to evaluate the services provided, which is a tool for measurement of the success in each individual case (Government of the Republic of Macedonia, 2006). Performance assessment of servants, not only by their immediate supervisors, but also with special legislation, has been stipulating setting up of traffic lights through which citizens can give their judgment and can share their experience when using public services. This is particularly important for interpersonal communication which is established between servants and citizens, and where subject of assessment is often the communication itself.

One of the last in the series of reforms undertaken in public administration is the project entitled There is no wrong door. Due to the complex organization of numerous governmental institutions, many people are not able to determine which institution is responsible for their need, and thus meet difficulties in communication with the administration. So they can feel rejected and frustrated in the search for a solution to 
their request. Citizens have high expectations of public institutions in the execution of public services. They want fast, efficient and quality service administration, regardless of time and place, which will be completed with courtesy, transparency and accountability by the servants. There is no wrong door concept is a new administrative approach that arises from the contemporary requirement which prescribe that the government should offer a service that will be citizen-oriented and will enable a better cooperation and coordination in the execution. This new modus operandi is innovative and has alternative approach in respect to the current work of the employees. By the means of it citizens will be obligatorily served, irrespective whether they have addressed the right office in the institution. This means abandoning the current practice of servants to work only within the individual jurisdictions, without giving any assistance or guidance to citizens how to access to the services provided by other competent authorities. It is important to note that this approach is currently practiced by numerous institutions, but the main idea is for it to become a habitual and purposeful behavior of every employee in the administration. For users of the administrative services, this means that the difficulties in communication with governmental institutions will reduce, thus leading to saving of resources and shortening the time to respond to their needs. The approach services to citizens is expected to improve the quality, but it will also eliminate the negative image of the public administration as unresponsive, atrophied, inefficient and indifferent to the needs and requests of citizens, in an easily accessible and citizen-oriented, with which the satisfaction with services will increase as well as the trust in public institutions (Ministry of Information Society and Administration, 2011).

Finally, raising the quality of public services, including interpersonal communication which takes place between servants and citizens, is one of the strategic goals contained in the Strategy for Public Administration Reform in the medium term and the Action plan for implementing this Strategy, Regulatory guillotine, one-stop-shop system, interoperability, electronic services, but also the Code of Ethics laid down by the Minister, which should ensure ethical, professional and responsible work. Therefore, it can be concluded that the actual reforms, and particularly their implementation in the public administration are still to come. The interpersonal communication between servants and service applicants will remain a top priority for all current and future creators of economic and communication policies in this sphere of social interest and social importance.

\section{Concluding remarks}

Finally, the most important thing in communication is hearing what is not said, wrote Peter F. Drucker. In today's world, the Holy Grail for the survival and development 
of the institutions may seek in the communication of their employees, particularly in the communication nexus with their clients. Namely, organizations are seriously suffering when interpersonal communication is ineffective. Therefore, errors that cause a lack of interpersonal communication, or irregular communication, contribute to increased communication costs, expressed through money, time and quality, which directly affects the performance component. This applies especially to relations with the outside world, because it leaves serious consequences for public relations, reputation and external communication. Successful organizations simply should not allow such things.

Effective interpersonal communication and information exchange will remove all doubts among citizens - beneficiaries of public services, something that is always present when there is a lack of information. Indeed, this does not affect the essential expression of public servants and the use of redundancy in the statements, a special feature of the ancient Romans, but it concerns the deficit of necessary and important information transmitted by interpersonal communication. Today, it can be freely said that information is the most powerful tool in modern society and in this sense it is a fundamental premise for successful, efficient and effective public management, emphasizing efficiency as its primary objective.

For the high or low quality of interpersonal communication in the public sector, assessments are multidirectional and can be obtained from different sources. The manifestations of the dimension of interpersonal communication appear as a determining factor in the successful service implementation within public sector. This confirms the outgoing considerations and interpretations of providing public services, as a process of interpersonal communication between entities, as well as the importance that there is communication within the process of their implementation.

Policymakers have a little misleading picture of interpersonal communication in their institutions or assume that it is on a higher level than the factual. In this regard, it is from a huge importance to increase the public awareness for identifying the level of interpersonal communication, detection of problems in communication needs and considering the possibilities for improvement through constant training of all organizational members. Despite all this, the process should always end with grading, remuneration and selection of the people and public institutions who in the past period achieved a remarkable progress and results to effective interpersonal communication between servant-citizen, much as it does the UK Public Sector. Concretely, the UK Public Sector each year gives the national award for outstanding communication strategies, campaigns and projects of local and national governmental and non-profit organizations in the UK, known as the Public Sector Communications Award.

In order to improve the interpersonal communication within public sector in the Republic of Macedonia, we propose various reforms, such as introducing training 
courses, establishing of communication offices, highlighting employees of the month who are best evaluated by citizens and superiors, as well as development and implementation of various comprehensive strategies, programs, policies and projects which significantly reduce the space for disqualifications, fighting words and hate speech (subject to restrictions under the Criminal Law). These steps would definitely improve the entire quality of interpersonal communication between servants and citizens.

The future of interpersonal communication is complex and ever-challenging. As a result, organizations are faced with numerous challenges, such as ethics and other rapid changes which are taking place in the institutional and social life. Accordingly, as the need and demand for knowledge continues to rise and intensify, the communication is placed in the focus on examination of organizational behavior and operations. Furthermore, the rapid progress of technology creates increased challenges and requirements to the organizational members. Interpersonal communication should be considered as a strategic issue and should be planned, developed, organized and controlled. Moreover, the paper shows that there is nothing mystical or vague about effective organizational communication. The main elements of communication are known and susceptible to measurement and evaluation.

At last, this extensive explication, though it identifies the root cause of the accidents and difficulties in interpersonal communication, it also shows our intention to point out to the importance of public servants, the place of citizens and their codes for organizations in which they work and act. Institutional communication as a controversial issue will continue to pose a challenge to the public administration in Macedonia, but we hope that the current negative practices would constitute an exception rather than a rule.

\section{References}

Argyris, C., Schon, D. (1978). Organizational learning: A theory of action perspective. Reading: Addison-Wesley.

Berger, C.R. (2008). Interpersonal communication. In: W. Donsbach (ed.). The international encyclopedia of communication (pp. 2473-2486). Malden: Blackwell Publishing.

Furnham, A., Petrova, E. (2010). Body language in business: Decoding the signals. New York: Palgrave Macmillan.

Galpin, T. (1995). Pruning the grapevine. Training \& Development, 49 (4), pp. 28-34.

Gjorgjijovski, B. (2012). Business communication (in Macedonian), mimeo.

Government of the Republic of Macedonia. (2006). Information on the introduction of an innovative and effective tool for improving public services and fight against bureaucracy and corruption Citizen's Charter. Skopje: Government of the Republic of Macedonia, Skopje.

Griffin, R.W. (2006). Principles of management. Mason: South Western, Cengage Learning.

Guffey, M.E., Loewy, D. (2011). Business communication, process and product. Seventh edition. Mason: South Western, Cengage Learning. 
Hamilton, C. (2008). Communicating for results: A guide for business and the professions. Eighth edition. Belmont: Thomson Wadsworth.

Hargie, O., Dickison, D., Tourish, D. (1999). Communication in management. Hampshire: Gower Publishing.

Jones, G.R., George, J.M. (2016). Contemporary management. Ninth edition. New York: McGraw-Hill Education.

Krizan, A.B.C., Merrier, P., Logan, J., Williams, K. (2008). Business communication. Seventh edition. Mason: Thomson South-Western.

Law on general administrative procedure, Official Gazette of the Republic of Macedonia, No. $124 / 2015$.

Law on administrative servants, Official Gazette of the Republic of Macedonia, No. 27/2014, 199/2014, 48/2015, 154/2015 and 5/2016.

Law on free access to public information, Official Gazette of the Republic of Macedonia, No. 13/2006, 86/2008, 6/2010, 42/2014 and 148/2015.

Law for employees of the public sector, Official Gazette of the Republic of Macedonia, No. 27/2014, 199/2014 and 27/2016.

Lehman, C.M. and DuFrene, D.D. (2011). BCOM. Mason: South Western, Cengage Learning.

Mehrabian, A. (1971). Silent messages. Belmont: Wadsworth.

Ministry of Information Society and Administration. (2011). No wrong door, the first door is the right door, Brochure. Skopje: Ministry of Information Society and Administration.

Rogers, E., Rogers, R. (1976). Communication in organization. New York: The Free Press, Macmillan Publishing.

Simon, H. (1947). Administrative behavior. Fourth edition. New York: The Free Press, Macmillan Publishing.

Stiglitz, J.E., Rosengard, J.K. (2015). Economics of the public sector. Fourth edition. New York: W.W. Norton \& Company.

Tapscott, D. (2008). Supervising Net Gen. Business Week Online, December $8^{\text {th }}$. Retrieved from: http://www.bloomberg.com/news/articles/2008-12-08/supervising-net-genbusinessweekbusiness-news-stock-market-and-financial-advice. 